\title{
Evaluating The Effectiveness of Gastroenterology e- Module for Undergraduate Medical Students, A Pilot Study From Syria
}

Bashar Almasri ( $\nabla$ dr.bashar.m@gmail.com )

Syrian Virtual University

Mayssoon Dashash

Syrian Virtual University

\section{Research Article}

Keywords: e-learning, e-module, gastroenterology, medical education, case-based learning.

Posted Date: September 7th, 2021

DOl: https://doi.org/10.21203/rs.3.rs-808231/v1

License: (c) (1) This work is licensed under a Creative Commons Attribution 4.0 International License.

Read Full License 


\section{Abstract}

\section{Background}

E-learning is an aspect of the practical application of pedagogy. Most students find it an entertaining and effective learning method. Also, case-based learning is related to pedagogy and is an interactive and enjoyable experiment for students. In Syrian medical schools, Gastroenterology teaching is depending on traditional teacher-centered style, passively affecting learning outcomes and imposing the search for other up-to-date alternatives.

The study aimed to evaluate the effectiveness of a case-based, E-Module of gastroenterology in fulfilling desired outcomes, and to evaluate students' satisfaction with the e-learning experiment, their selfconfidence improvement, and their perception of the experiment's obstacles.

\section{Methods}

13 undergraduate medical students were enrolled. A pretest was conducted, then they participated in 6 synchronous online lectures, and 6 asynchronous lectures which were subjects to the discussion. Students then took a posttest and answered a questionnaire composed of 15 questions measuring their satisfaction with the experiment, self-confidence improvement, and obstacles they faced.

\section{Results}

The mean students' degrees in the pretest was $41.5 \%$, while it was $66.8 \%$ in the posttest with a statistically significant difference. There was no statistical difference in posttest between students' answers regarding synchronous lectures compared with asynchronous ones. The best results were related to students' perception of self-confidence improvement after the e-learning experiment.

\section{Conclusions}

E-learning plays an important role regarding students' level of knowledge improvement. Most of the participants show satisfaction with their knowledge and self-confidence improvement after the E-learning experiment.

\section{Introduction:}

The COVID-19 pandemic cast its shadows all over the world and resulted in important social and economic sequences. By the end of March 2020, more than 166 countries implemented measurements of lockdown and social distancing, leading to many consequences on the educational process at all levels. UNESCO estimated that about 1.5 billion students are affected, and more than 60 million teachers left their classrooms (1). 
The organization recommended shifting to online and E-learning to continue the educational process. Although e-learning is an old and commonly used method in many countries, it is a rarely-used method in Syria, whether by governmental or private universities, except for the open-learning and virtual university experiments.

Implementing e-learning is considered a practical application of adult learning theory. It allows teachers to act as educational guidance and facilitators instead of the routine teaching role $(2,3)$. Most students find e-learning an effective and entertaining learning method, but they don't think that it can replace the traditional learning method (4).

Medical e-learning in Syria is limited to some students' initiatives, such as the production or translation of educational videos and uploading them to social networks like YouTube (5). Medical education in Syrian medical schools, either public or private, depends on the traditional style, represented by direct lectures and indoctrination. Students' role is almost always passive. This reflects the need for investigating elearning systematically, as it can later be universally adopted.

\section{Methods:}

Our study aimed to design and implement an e-module of gastroenterology for medical undergraduate students, and evaluate its effectiveness in achieving required educational outcomes, and assessing students' satisfaction with e-learning experiment, the improvement of students' self-estimation, and their perception about experiment's obstacles.

A pilot, single-university prospective study involving undergraduate medical students was conducted. We designed an e-module of gastroenterology in a case-based style, approaching a specific case in each educational unit. Each unit has specific known educational objectives mentioned at the beginning of the unit. A case scenario related to the unit's subject is presented for discussion, then the unit's contents are outlined as etiology, diagnosis and differential diagnosis, management, and prognosis. The scientific content was arranged depending on Davidson's Principles and Practice of Medicine 21st ed. and Macleod's Clinical Examination 13th ed. Twelve educational units were designed and divided according to delivery type into 6 synchronous and 6 asynchronous units. Educational units were designed as slides with Microsoft PowerPoint 2016.

26 students were chosen randomly from AlKalamoon university medical school by an announcement through social media. The students were tested by a pretest composed of 25 multiple-choice questions presented by a google form and results were gathered.

Synchronous lectures were introduced within 3 weeks (2 lectures a week) through Google meet with voice and slides sharing, discussing subjects, and answering students' questions about differential diagnosis, diagnostic methods, management, and prognosis for each case. 
All lectures (synchronous and asynchronous) were uploaded to the Syrian virtual university's learning management system, so accession to the module can be tracked. Students were able to download lectures and send their questions and notes through email or discussion forums. All students' queries were discussed and answered.

A posttest (different from pretest but similar in difficulty and design) was shared with students who completed the course as a google form, and results were gathered. Also, a self-assessment survey based on a five-point Likert-type scale (6) was filled by students. The survey included 15 questions categorized into 3 groups, each one consisted of 5 questions measuring participant's satisfaction, self-confidence, and experiment obstacles. Each question has 5 answers (strongly agree, agree, neither agree nor disagree, disagree, strongly disagree), and points are given for each answer as $(5,4,3,2,1$ point) respectively when the question is positive and in the opposite way when it is negative. Points for the whole survey and each included category were collected. The interpretation of the whole survey's points was as follows (15-35 means bad perception, 36-55 means good perception with a need to improve, and 56-75 means excellent perception), and the interpretation of each category's points was as follows (5-11 means bad perception, 12-18 means good perception with a need to improve, and 19-25 means excellent perception). Statistical analysis was performed using Microsoft Excel 2016 and IBM SPSS Statistics v.20. $p$-value $<0.05$ was considered to evaluate statistical significance.

\section{Results:}

Out of 26 students who answered the pretest, only 13 continued to attend the online lectures, download documents (tracked by LMS), and fill the posttest and survey. So that the final sample was 13 students included 3 males and 10 females, 11 from the fifth academic year, 1 from the fourth year, and 1 from the sixth year. Most of the participants had already received education in gastroenterology during medical school years (23 out of 26), and most had been involved previously in e-learning experiments (16 out of 26).

The 26 students' average degree of the pretest was $38.77 \%$. Table 1 and Fig. 1 compare the results of preand post-test of the 13 students.

Table 1

comparison of pre-and post-test results

\begin{tabular}{|llll|}
\hline & pretest & posttest & P value \\
\hline Degrees range & $28-56 \%$ & $40-84 \%$ & \\
\hline Degrees mean & $41.5 \%$ & $66.8 \%$ & 0.00004 \\
\hline
\end{tabular}


The results of the posttest were further analyzed, comparing the answers of students about subjects related to synchronous lectures with those related to asynchronous ones, right answers were $66.7 \%$ of synchronous lectures vs. $66.8 \%$ of asynchronous ones. The $p$-value was statistically not significant (0.48).

Regarding the assessment survey, Cronbach's alpha coefficient was calculated to ensure internal consistency for the whole survey and each category included in it (Table 2).

Table 2

Cronbach's alpha coefficient for internal consistency

\begin{tabular}{|ll|}
\hline Survey's category & Cronbach's alpha coefficient \\
\hline Students' satisfaction & 0.79 \\
\hline Self-confidence improvement & 0.67 \\
\hline Experiment's obstacles & 0.56 \\
\hline The whole survey & 0.82 \\
\hline
\end{tabular}

The best response of students was about the improvement of their self-confidence following the elearning experiment, while the worst perception was about the experiment's obstacles (Table 3 and Table 4). 
Table 3

Survey's results- 1

Number of answers

Mean

of

points

Strongly Agree Neither Disagree Strongly agree

disagree

\section{Perception of students' satisfaction} after e-learning experiment

You feel your participation was

1

10

2

0

effective in improving your

information

You find e-learning more flexible

2

6

3

1

1

3.5

than traditional one

You feel e-learning help in time

2

8

2

0

3.8

management better than traditional

one

You find e-learning more entertaining than traditional one

You feel medicine is hard to be remotely taught *

1

3

\section{Perception of students' self- confidence after e-learning experiment}

You feel your familiarity with $\mathrm{GI}$ diseases is now better

You feel more capable to answer GI questions in NBE after the course

You feel more capable to systemically approach patients with Gl problems

You aren't yet capable to diagnose and treat GI diseases *

The course gave you the passion to proceed to the Gl residency program

\section{Perception of experiment's} obstacles

1

9

2

1

0

3.8

0

7

6

0

0

3.5

1

11

1

0

4

3.5

E-learning is less costly than traditional one

You feel e-learning needs high technological abilities *
0

0

6

6

3

4

0

2.8

0

5

6

2

0

3.2 
Bad internet connection prevented 2 you from effectively participating in

2

$2 \quad 1$

3.2

the course *

You think that lack of direct contact 2 reduces the effectiveness of $\mathrm{e}^{-}$

2

$8 \quad 0$

learning *

You had no difficulties handling e- 2

learning technologies

$\begin{array}{lllll}6 & 1 & 4 & 0 & 2.5\end{array}$

* negative question

Table 4

Survey's results-2

\begin{tabular}{|lllll|}
\hline $\begin{array}{l}\text { Participant's } \\
\text { number }\end{array}$ & $\begin{array}{l}\text { Perception of } \\
\text { students' satisfaction }\end{array}$ & $\begin{array}{l}\text { Perception of students' } \\
\text { self-confidence }\end{array}$ & $\begin{array}{l}\text { Perception of } \\
\text { experiment's obstacles }\end{array}$ & Total \\
\hline $\mathbf{1}$ & 16 & 14 & 16 & 46 \\
\hline $\mathbf{2}$ & 23 & 18 & 16 & 57 \\
\hline $\mathbf{3}$ & 19 & 16 & 18 & 53 \\
\hline $\mathbf{4}$ & 10 & 16 & 15 & 41 \\
\hline $\mathbf{5}$ & 12 & 17 & 17 & 46 \\
\hline $\mathbf{6}$ & 15 & 18 & 16 & 49 \\
\hline $\mathbf{7}$ & 15 & 17 & 12 & 44 \\
\hline $\mathbf{8}$ & 20 & 17 & 18 & 55 \\
\hline $\mathbf{9}$ & 16 & 14 & 10 & 40 \\
\hline $\mathbf{1 0}$ & 20 & 20 & 17 & 57 \\
\hline $\mathbf{1 1}$ & 21 & 22 & 21 & 64 \\
\hline $\mathbf{1 2}$ & 20 & 19 & 18 & 57 \\
\hline $\mathbf{1 3}$ & 16 & 18 & 20 & 54 \\
\hline Mean & $\mathbf{1 7} / 25$ & $\mathbf{1 7 . 4 / 2 5}$ & $16.5 / 25$ & $\mathbf{5 1}$ \\
\hline
\end{tabular}

Discussion: 
Rapid technology evolutions led to the release of new learning patterns. E-learning is an interactive activity that aims to deliver knowledge, skills, and attitudes to the learner through direct and indirect ways using information and communication technology (7). The importance of e-learning lies in solving the problem of informative explosion and widening the learning opportunities to include overseas people, also it provides flexibility and a more systematic approach to learning (3). We aimed to design and evaluate an e-learning based course in gastroenterology for medical students in Syria.

Most participants in our study were female students, reflecting the increased desire to explore new learning methods in females. Although most participants had past education in GI diseases, the degrees of the pretest were relatively low (16 to 60\%), which reflects the poor curriculum presented to students in medical school. Most students in the study had experience in e-learning during the COVID-19 pandemic and universities lockdown in 2020.

When we started the course, one-half of the students went off the study. Some of those show discomfort with the bad internet connection or the unsuitable timing of synchronous lectures.

Comparing the results between pretest and posttest, we noted good improvement in students' knowledge. The mean degree of participants was $41.5 \%$ in pretest, rising to $66.8 \%$ in post-test with a statistically significant difference. This refers to the e-module effectiveness in improving the level of students' knowledge and information.

Comparing results of synchronous and asynchronous lectures showed no difference. We can conclude that students' participation in synchronous lectures did not add a benefit to downloading and reading lectures, with further asynchronous discussion with the tutor.

When students are asked to evaluate their participation in the course through the final survey, we can conclude the following:

- The internal consistency was good for the whole questionnaire and knowledge improvement category, still acceptable for the self-confidence category, but poor for the obstacles category which means that some questions in the last one need to be modified (8).

- Most students felt improvement in knowledge.

- Most participants felt e-learning is more flexible and gives more time management ability.

- One-half of participants felt that e-learning is more entertaining while one-third found traditional one is better.

- More than $50 \%$ of participants believed that medicine is hard to be learned remotely.

- Self-confidence was improved after the e-learning experiment, this was reflected by the feeling of knowledge improvement, feeling able to solve NBE questions, and the improvement of GI symptoms approach by most participants.

- Less than one-half of students felt more tendency to GI specialty after the course. 
- Regarding e-learning obstacles, most of the participants found e-learning less expensive and didn't feel upset about bad internet connections or technological difficulties.

Comparing our study with other studies shows similar results, for example, the systematic review of Barteit et al (9) showed good results of e-learning in low-income countries (like Syria). Participants' satisfaction after course completion was good also in the study of Borakati (10). Dost et al (11) found out that the best impression was about e-learning flexibility and the most important obstacle was the family distraction and the bad internet connection, while the best benefit in our study was the improvement in self-confidence and the major obstacle was the absence of direct contact. Unlike our results, Khasawneh et al (12) found that e-learning didn't improve the level of knowledge.

\section{Conclusion:}

We concluded that e-learning plays an important role in improving the level of knowledge, with no difference between synchronous and asynchronous methods. Most of the participants express good satisfaction with the improvement of their knowledge and self-confidence. The major barrier is the absence of direct contact in e-learning, while the effect of other difficulties regarding internet connection and technical issues was neglected.

\section{List Of Abbreviations}

\section{UNESCO}

The United Nations Educational, Scientific and Cultural Organization

\section{LMS}

Learning Management System

$\mathrm{GI}$

Gastro-Intestinal

\section{Declarations}

\section{Ethics approval and consent to participate}

Ethical approval was given by ethics committee of Syrian virtual university. Informed consent was obtained and signed by each participant before starting the course.

\section{Consent for publication}

Not applicable

\section{Availability of data and materials}

The datasets used and/or analyzed during the current study are available from the corresponding author on reasonable request. 


\section{Competing interests}

The authors declare that they have no financial or non-financial competing interests

\section{Funding}

No funding sources

\section{Authors' contributions}

Bashar Almasri has designed the curriculum, implemented the online course, analyzed the results, and written the manuscript

Maysoon Dashash has supervised the designation and implementation of the course.

All authors read and approved the final manuscript

\section{Acknowledgements}

Not applicable

\section{References}

1. Maneiro S. Coronavirus COVID-19 and Higher Education: Impact and Recommendations - UNESCO 2020 [updated May 10, 2021. Available from:

http://www.iesalc.unesco.org/en/2020/03/09/coronavirus-covid-19-and-higher-education-impactand-recommendations/.

2. Ruiz JG, Mintzer MJ, Leipzig RM. The impact of E-learning in medical education. Academic medicine: journal of the Association of American Medical Colleges. 2006;81(3):207-12.

3. Regmi K, Jones L. A systematic review of the factors - enablers and barriers - affecting e-learning in health sciences education. BMC Medical Education. 2020;20(1):91.

4. Warnecke E, Pearson S. Medical students' perceptions of using e-learning to enhance the acquisition of consulting skills. The Australasian medical journal. 2011;4(6):300-7.

5. Kouba L, Amin B, Azzam A. Online education opportunity for Syria's future doctors. Lancet (London, England). 2019;394(10211):1805-6.

6. Joshi A, Kale S, Chandel S, Pal D. Likert Scale: Explored and Explained. British Journal of Applied Science \& Technology. 2015;7:396-403.

7. Khalil R, Mansour AE, Fadda WA, Almisnid K, Aldamegh M, Al-Nafeesah A, et al. The sudden transition to synchronized online learning during the COVID-19 pandemic in Saudi Arabia: a qualitative study exploring medical students' perspectives. BMC Medical Education. 2020;20(1):285.

8. Ursachi G, Horodnic IA, Zait A. How Reliable are Measurement Scales? External Factors with Indirect Influence on Reliability Estimators. Procedia Economics and Finance. 2015;20:679-86. 
9. Barteit S, Guzek D, Jahn A, Bärnighausen T, Jorge MM, Neuhann F. Evaluation of e-learning for medical education in low- and middle-income countries: A systematic review. Computers \& Education. 2020;145:103726.

10. Borakati A. Evaluation of an international medical E-learning course with natural language processing and machine learning. BMC Medical Education. 2021;21(1):181.

11. Dost S, Hossain A, Shehab M, Abdelwahed A, Al-Nusair L. Perceptions of medical students towards online teaching during the COVID-19 pandemic: A national cross-sectional survey of $2721 \mathrm{UK}$ medical students. BMJ Open. 2020;10:42378.

12. Khasawneh R, Simonsen K, Snowden J, Higgins J, Beck G. The effectiveness of e-learning in pediatric medical student education. Medical education online. 2016;21:29516.

\section{Figures}

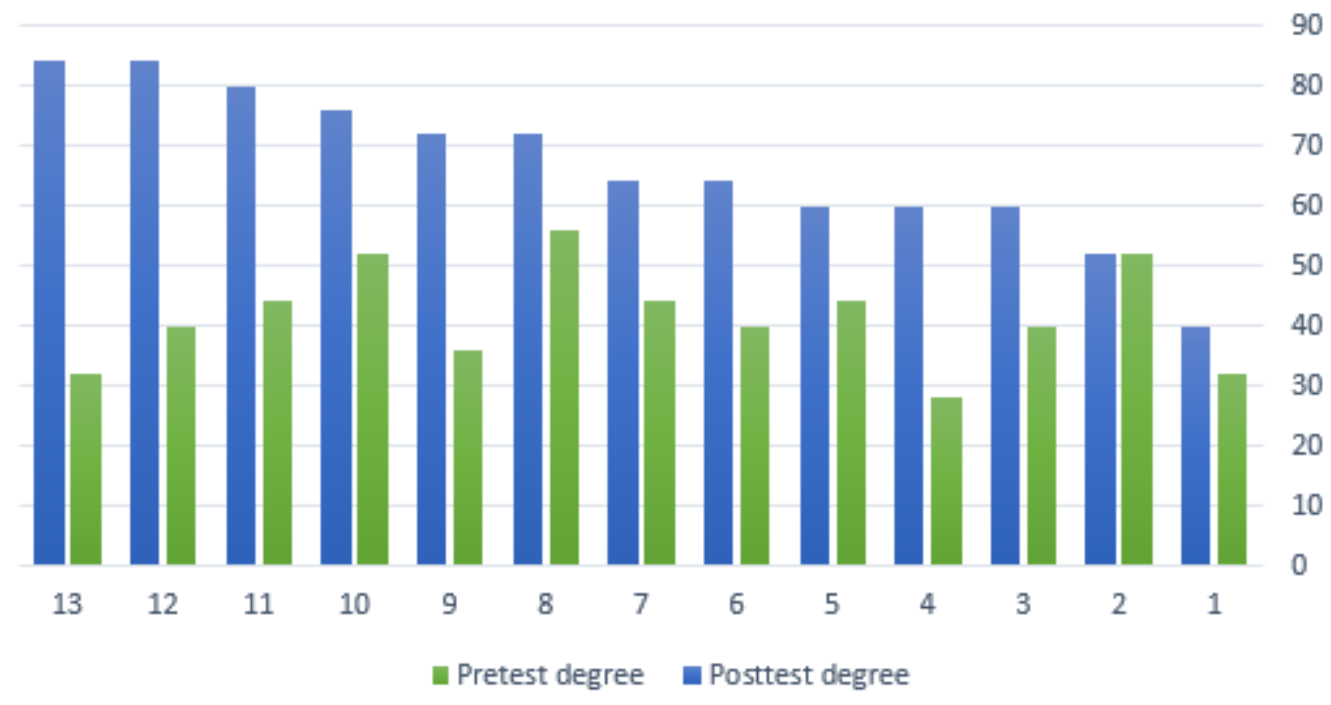

Figure 1

Comparison of pre- and post-test results 